\title{
Magnetic Survey of Taiwan and Its Preliminary Interpretations
}

\author{
Horng-Yuan Yen ${ }^{1,}$, Chieh-Hung Chen ${ }^{2}$, Hsien-Hsiang Hsieh ${ }^{1}$, Ching-Ren Lin ${ }^{1,2}$, \\ Yih-Hsiung Yeh ${ }^{2}$, Yi-Ben Tsai ${ }^{1}$, Jann-Yeng Liu ${ }^{3}$, Guey-Kuen $\mathrm{Yu}^{4}$, and Yi-Ru Chen ${ }^{1}$ \\ ${ }^{1}$ Institute of Geophysics, National Central University, Chung-Li, Taiwan, ROC \\ ${ }^{2}$ Institute of Earth Sciences, Academia Sinica, Taipei, Taiwan, ROC \\ ${ }^{3}$ Institute of Space Science, National Central University, Chung-Li, Taiwan, ROC \\ ${ }^{4}$ Department of Civil Engineering, Vanung University, Chung-Li, Taiwan, ROC
}

Received 15 August 2007, accepted 8 April 2008

\begin{abstract}
To achieve an improved overall understanding of the tectonics of Taiwan, an island-wide magnetic survey, especially in the mostly inaccessible mountain ranges, was carried out from July 2003 to February 2004. In total, 6063 magnetic points were surveyed at an average spacing of $2 \mathrm{~km}$. After data reductions, a new magnetic anomaly map of Taiwan was constructed. The map shows the range of magnetic anomalies mostly distributing between -400 to $400 \mathrm{nT}$. Anomalies in the southern part of Taiwan are much higher than those in the north whilst anomalies in the western plains area are higher than those of the mountain ranges.

High-frequency magnetic anomalies, generally more complex and localized, are found in west central (south of $24^{\circ} \mathrm{N}$ ) and southwestern Taiwan. Smooth and gentle magnetic anomalies lie over a major part of the mountain ranges, except in the southern segment of the Central Range. According to the amplitude of magnetic anomalies and their coverage, this implies that a broad extrusive ultramafite body could exist beneath the southern segment of the Central Range.
\end{abstract}

Key words: Magnetic survey, Magnetic anomaly, Diurnal variation, IGRF

Citation: Yen, H. Y., C. H. Chen, H. H. Hsieh, C. R. Lin, Y. H. Yeh, Y. B. Tsai, J. Y. Liu, G. K. Yu, and Y. R. Chen, 2009: Magnetic survey of Taiwan and its preliminary interpretations. Terr. Atmos. Ocean. Sci., 20, 309-314, doi: 10.3319/TAO.2008.04.08.01(T)

\section{INTRODUCTION}

Magnetic anomalies are the result of contrasts in magnetization due to susceptibility contrasts in crustal rocks of different magnetic properties. Comprehensive magnetic anomaly maps are essential for a complete understanding of regional tectonics and geological characteristics.

Magnetic anomaly maps of Taiwan have been constructed previously by the Chinese Petroleum Corporation for oil exploration (Hsieh and $\mathrm{Hu}$ 1972; Chang and $\mathrm{Hu}$ 1981). In general, their data, however, are restricted to potential oil-reserve areas, mostly over the western plains region. In addition, Hsu et al. (1998) compiled both land and marine magnetic data to illustrate several new insights into the Taiwan-Luzon region. Wang et al. (2002) used this magnetic evidence to describe the formation of Taiwan as a solitary wave along the Eurasian continental plate margin. How-

\footnotetext{
* Corresponding author

E-mail:yenhy@earth.ncu.edu.tw
}

ever, none of these surveys provided much data on the mountainous regions of Taiwan. Consequently, until a recent comprehensive magnetic anomaly survey, Taiwan's magnetic data was incomplete, especially in the inaccessible mountainous regions.

The comprehensive magnetic survey of the whole island was conducted from July 2003 to February 2004 via a joint effort between the Institute of Geophysics, National Central University and the Institute of Earth Sciences, Academia Sinica. Much thoughtful planning regarding the utilization of instruments, manpower, and survey routes was required to reduce the effects of geomagnetic secular variations. All magnetic points were surveyed with an average spacing of $2 \mathrm{~km}$ along highways, byways, and mountainous trails (Fig. 1). This paper describes the magnetic survey and construction of the magnetic anomaly map based on these new magnetic data. In addition, preliminary interpretations of the tectonic significance of these maps are also discussed. 


\section{GEOLOGY AND TECTONIC SETTING OF TAIWAN}

Taiwan is the result of complicated interaction between two converging plates, the Eurasian plate to the northwest and the Philippine Sea plate to the southeast. The complications arise due to a change in subduction polarity in the vicinity of Taiwan and the fact that the North Luzon arc, on the Philippine Sea plate, intersected the Eurasia continental margin (Fig. 2) following the subduction of the oceanic and transitional lithosphere of the Eurasian plate. The mountains in Taiwan are very young, geologically speaking, formed as a result of the collision between an island arc system and the Asian continental margin (Wu 1978; Ho 1982; Tsai 1986).

The geological structures of Taiwan trend mainly in a NNE-SSW direction as shown in the simplified geological map of Fig. 2. These trends are parallel to the main topographic trends. The surface geology of Taiwan is dominated by Tertiary rocks, except on the east side of the Central Range, where pre-Tertiary metamorphic complexes are exposed.

East of the metamorphic complex is the Coastal Range, where Miocene and younger rocks representing a former is-

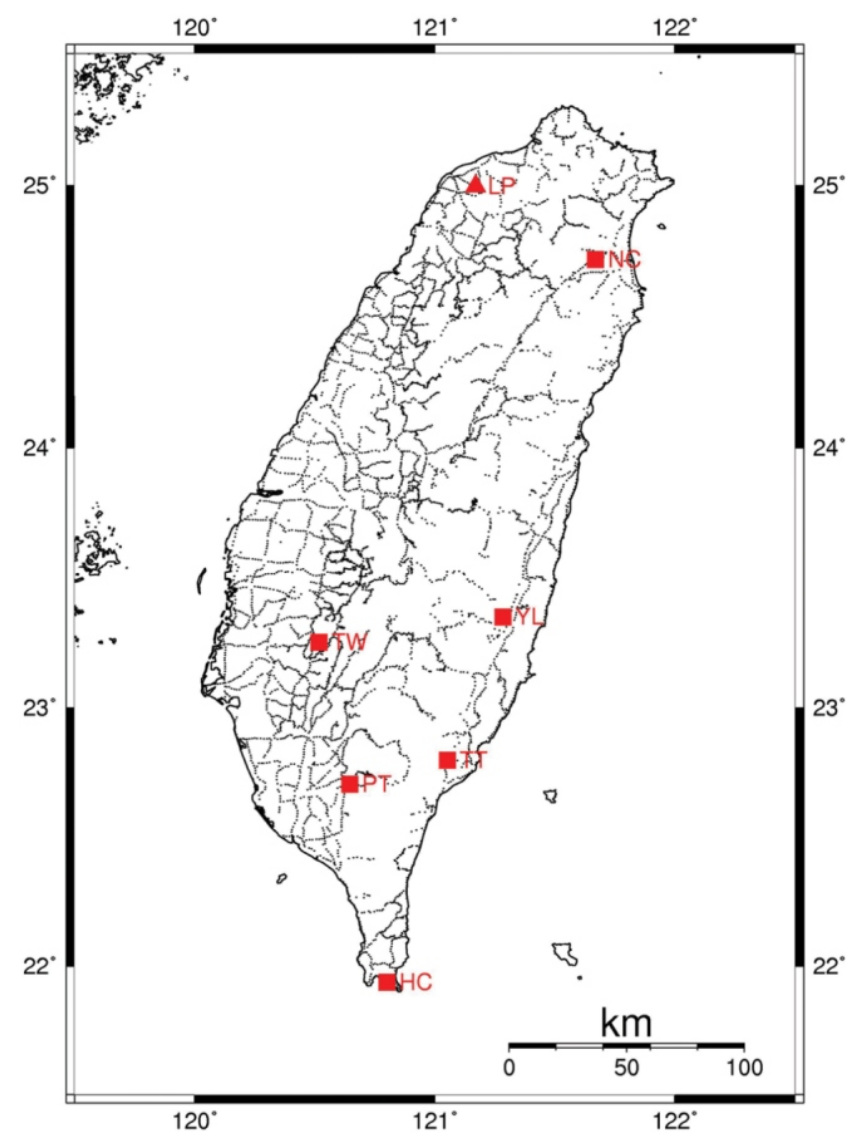

Fig. 1. Magnetic measuring points in Taiwan ( $\square$ : geomagnetic permanent station to correct the diurnal variations, $\mathbf{\Delta}$ : reference station in the old geomagnetic network). land arc are found. These rocks composed of andesitic volcanic units are thrust up along a series of en echelon faults, and these thrust blocks were successively accreted to the island, beginning around 4 - 6 mybp (Lee et al. 1991). The Longitudinal Valley (LV) separates the Coastal Range from the Central Range to the west. The LV is considered to be the suture that juxtaposes older continental rocks and young island arc materials.

West of the pre-Tertiary metamorphic complex are the main Central Range, the Foothills, and the Coastal Plain. In northern Taiwan, the Central Range is composed of two ranges, the Backbone Range in the east and the Hsuehshan Range in the west, but the southern Central Range is a single range. The Backbone Range is composed mainly of slates, but in the Hsuehshan Range alternating sandstone and shale layers dominate. Most of the older Tertiary rocks were derived from the Chinese mainland, but since the Late Pliocene, sediments in the western Taiwan Basin have come from the Central Range (Chou 1973), signifying the rise of the Central Range at that time. The Coastal Plain of western Taiwan is composed of Quaternary alluvial deposits, and the Neogene strata underneath are gently folded and thin to the west. The Peikang high, where the pre-Tertiary basement is at the shallowest in western Taiwan, is a natural divide between north and south Taiwan. The other prominent basement is called the Kuanying high, which underlies the north-

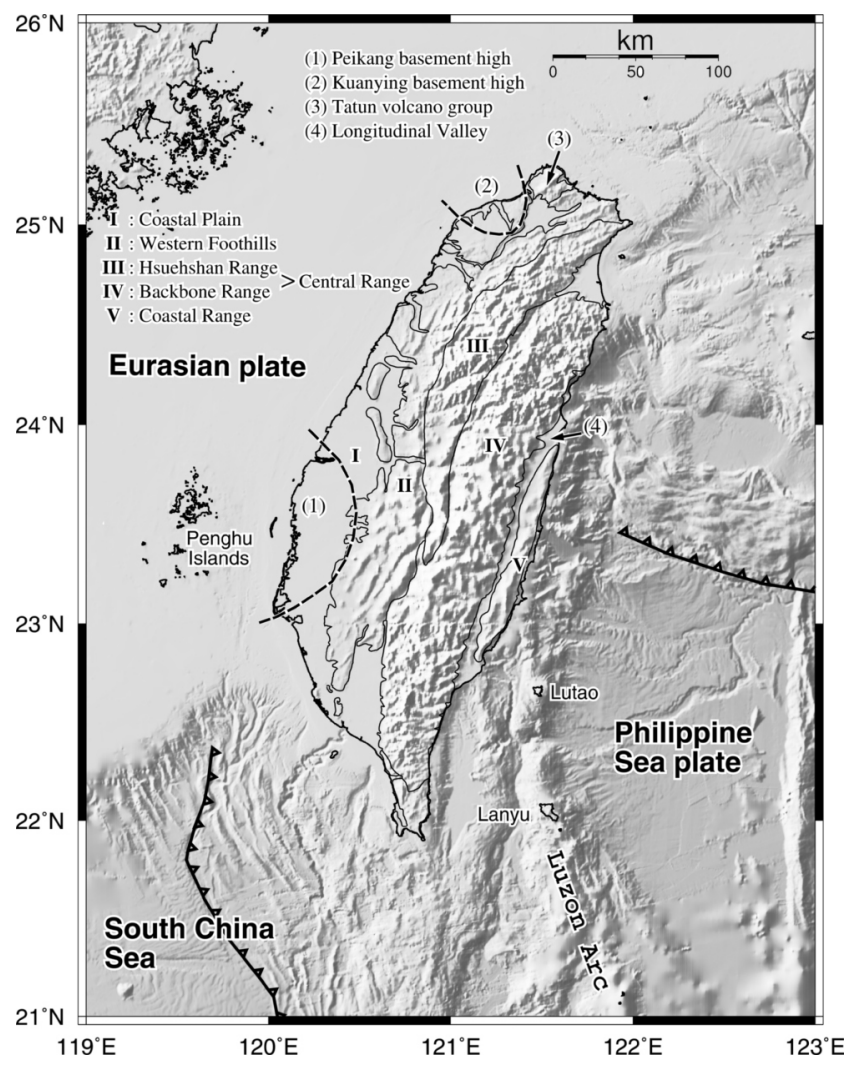

Fig. 2. Topography and geological settings of the Taiwan region (After Ho 1982). 
western offshore area (Sun and Hsu 1991).

An additional feature is the Tatun andesitic volcano group located at the northern tip of the island. It is believed to be associated with the subduction of the Philippine Sea plate (Chen 1975).

\section{MAGNETIC SURVEY AND REDUCTIONS}

A new geomagnetic network of twelve stations equipped with continuous recording systems (GSM90F with $0.1 \mathrm{nT}$ sensitivity and $1 \mathrm{~min}$. sampling rate) was established by the Institute of Geophysics, National Central University (Yen et al. 2004). All the magnetic instruments were checked simultaneously at the Lunping (LP) station, an old reference station of the island-wide geomagnetic network previously deployed. Six geomagnetic permanent stations (Fig. 1) from the new geomagnetic network were chosen to monitor diurnal variations in the earth's magnetic field. Of these stations, the Tsengwen (TW) station is located in western Taiwan while the other five stations: Neicheng (NC), Yuli (YL), Taitung (TT), Hengchun (HC), and Pingtung (PT) are distributed over eastern and southern Taiwan.

Ten portable proton precession magnetometers (including Geometrics models G-826/G-856 with sensitivity $1 / 0.1 \mathrm{nT}$, respectively) were used in the island-wide magnetic surveys. These instruments were calibrated at the TW station prior to deployment to correct any systematic variation in each instrument.

The Central Range of Taiwan, reaching nearly $4000 \mathrm{~m}$ in elevation at its highest point, is an area where few magnetic measurements were taken prior to 2002 (Hsu et al. 1998; Wang et al. 2002). To achieve an improved overall understanding of the tectonics of Taiwan, especially in the more inaccessible mountainous regions, an island-wide magnetic survey was initiated in July 2003 and completed in February 2004. In total, 6063 magnetic points were surveyed (Fig. 1). Efforts were made to provide as uniform coverage in the mountain ranges as physically possible.

Each magnetic point was chosen after careful inspection of the surrounding area. Basically, points were selected far away from populated areas, all visible iron objects and power lines to avoid unwanted or manmade "noises" and interference. To ensure measurement reliability, five readings of total magnetic intensity were measured over a few minutes at each magnetic point. If the standard deviation among readings was less than $10 \mathrm{nT}$, which is considered the diurnal variations of Taiwan (Yeh et al. 1981; Chen et al. 2004), the observed readings were averaged as the total magnetic intensity of the given point. The location and elevation of the magnetic points and the observed time were determined by a portable GPS accurate enough for this largescale survey.

Diurnal variation is due to the part of the earth's magnetic field originating in the ionosphere. At any point on the earth's surface the external field varies with a range of amplitude of about 10 - $30 \mathrm{nT}$ during the day (Chapman and Bartels 1940) as the earth rotates beneath different parts of the ionosphere. The magnitude of the diurnal variation depends on the latitude at which it is observed. For the Taiwan region, the magnitude of diurnal variation is $10-50 \mathrm{nT}$ (Chen et al. 2004). Diurnal variation may be corrected by installing a constantly recording magnetometer at a fixed base station within the survey area generally. Records from the geomagnetic permanent station (Fig. 1) nearest the measuring point can be used to correct the diurnal variations.

In regional studies, corrections for latitude and longitude are inherent in the reference field that is subtracted. The International Geomagnetic Reference Field (IGRF), for the field of internal origin and its secular variation (Regan and Cain 1975; Barton 1997), was promulgated by the International Association of Geomagnetism and Aeronomy (IAGA) Commission 2. A global model of the reference field is calculated by:

$$
V=R \sum_{n=1}^{N} \sum_{m=0}^{n}\left(\frac{R}{r}\right)^{n+1}\left(g_{n}^{m} \cos m \phi+h_{n}^{m} \sin m \phi\right) P_{n}^{m}(\cos \theta)
$$

Here, $V$ is the theoretical earth's magnetic intensity by IGRF; $R$ is the earth's average radius; $r$ is the distance from the measuring point to the earth's center; $g$ and $h$ are the Gauss coefficients of degree $n$ and order $m$; $\phi$ is the longitude; $\theta$ is the geocentric co-latitude; and $P(\cos \theta)$ are called Legendre polynomials $(m=0)$. In this study, the spherical harmonic coefficients up to $n=13$ are based on IGRF version 9 to calculate the normal magnetic value (http://www .ngdc.noaa.gov/IAGA/vmod/igrf.html, 2003). The vertical gradient clearly depends on the latitude of the measuring point. The elevation correction, especially in areas of rugged topography, must be considered to be about $0.023 \mathrm{nT} \mathrm{m}^{-1}$ for Taiwan (Chen 2005).

\section{MAGNETIC ANOMALY MAP}

After corrections, a magnetic anomaly map (Fig. 3) was constructed from the newly collected data. This map differs significantly from previous maps, which were based on insufficient data from the Central Range. The map is generally more complex and variations in field more erratic and localized than the gravity map (Yen et al. 1998). As Fig. 3 shows, the range of the magnetic anomaly distributes between -400 $\sim 400 \mathrm{nT}$ over Taiwan. Anomalies are much higher in the south than in the north; and those of the western plains area are higher than those in the mountain ranges.

Although such an interpretation of the magnetic anomaly distribution is still far from unique, it does provide several interesting and significant insights about Taiwan within the new map. A high-frequency, positive, magnetic 


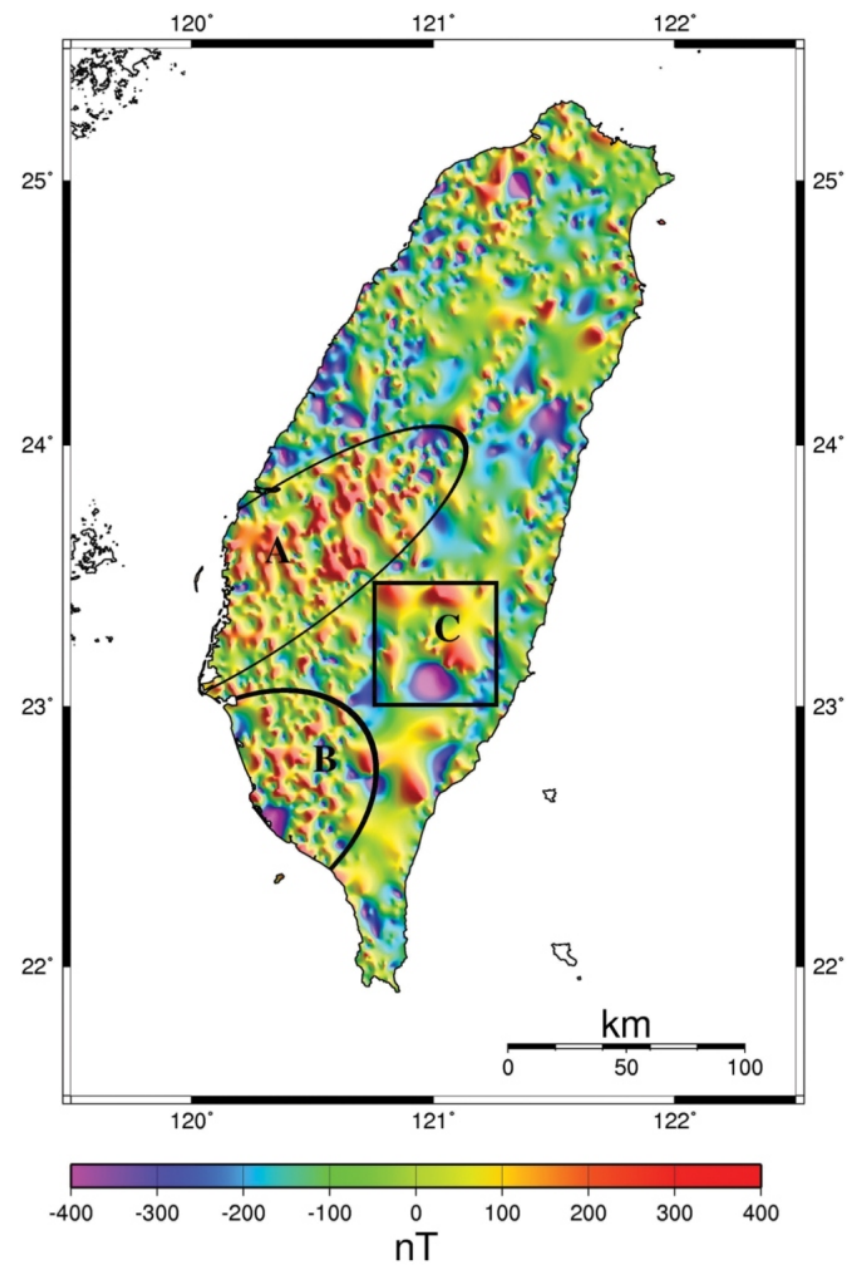

Fig. 3. Magnetic anomaly map of Taiwan with a contour of $100 \mathrm{nT}$. Interestingly, the southern segment of the Central Range is in a conspicuous magnetic anomaly with a 500-nT anomalous range, over an area of roughly $50 \times 50 \mathrm{~km}^{2}$. (A region: from the Peikang basement high, ending in central Taiwan; B region: southwestern Taiwan; $\mathrm{C}$ region: the southern segment of the Central Range).

anomaly trending NE-SW manifests as a prominent (Zone A of Fig. 3), continuous high from the Peikang basement high, extending as far as central Taiwan (around $121^{\circ} \mathrm{E}$ and $24^{\circ} \mathrm{N}$ ). It is well known that an anomalous area over the Coastal Plain is associated with the Peikang high. This anomaly belt relates to the shallowness of the Cretaceous basement, something that is well documented in drilling data (Tang 1977). This positive magnetic anomaly belt also extends southwestward to the Penghu islands (Hsu et al. 1998), formed by extrusive basalts with strong thermoremanent magnetization (Gao and Huang 1994). Further northeast of the Peikang basement high, one would expect the magnetic anomaly to decrease, since low-grade metamorphosed pre-Neogene sandstone and slate with low magnetic susceptibility, are exposed, but in fact, a high-frequency anomaly presents around the middle part of the Western Foothills and Hsuehshan Range. This somewhat incongruent result is also found on the Bouguer anomaly distribution of this area (Yen et al. 1995). As a result of this finding, the tectonic implications for central Taiwan and its actual mechanism will be investigated further using seismic experiments. Another highfrequency anomaly is also found in southwestern Taiwan (Zone B of Fig. 3), an area filled with natural greigite/ pyrrhotite-bearing sediments (Horng et al. 1992; Torii et al. 1996).

Negative anomalies cover west central Taiwan, over Tertiary and Quaternary sedimentary basins. Two minor magnetic anomalies appear on the northern extremity of the island. One is located over the Kuanying basement high, a shallow pre-Tertiary basement characterized by tectonic stability. The other is over the Tatun Volcano Group, covered with andesitic lavas and pyroclastics. In addition, a magnetic anomaly is found in the Coastal Range where the telescoped Luzon arc is composed of young igneous materials.

The smooth and gentle magnetic anomalies over a major part of the Backbone Range and the Hsuehshan Range indicate that the metamorphic rocks of those regions are composed of the low-susceptibility materials, such as slates, marbles, amphibolites and quartzites. It is interesting to note that the southern segment of the Central Range (Zone C of Fig. 3), an area of roughly $50 \times 50 \mathrm{~km}^{2}$, exhibits a conspicuous magnetic anomaly with about a 500-nT anomalous range. This unexpected magnetic anomaly seems to contradict antecedent understandings.

In the past, few geophysical and geological observations of the southern segment of the Central Range were reported due to extremely difficult accessibility. Therefore, the overall tectonic structure of the southern segment of the Central Range remains obscure and the subject of wide debate. The heat flow map in Taiwan is basically constructed according to measured heat flow near the surface, mostly over the Coastal Plain and the Western Foothills (Lee and Cheng 1986). The heat flow increases from west to east, reaching its peak over $200 \mathrm{~mW} \mathrm{~m}^{-2}$ in the Central Range, particularly between 23 and $24^{\circ} \mathrm{N}$. One of the most significant features is a persistent aseismic area, more or less the same as the magnetic anomaly region. This lack of seismicity here has been attributed to enhanced ductility of rocks in the Central Range, an important parameter in the geodynamics of orogeny (Wu et al. 1997). The higher temperatures produced by the exhumed crust exposed on the southern segment of the Central Range are consistent with the higher heat flow observed on the surface and the aseismic zone within the upper crust (Lin 2000). The tectonic compression, especially in the Central Range, involves the lithosphere and is characterized by a strong coherent deformation of the upper mantle and the crust, based on examined shear wave splitting in SKS phases from a large event recorded by a temporary array across southern Taiwan (Huang et al. 2006).

In addition, on geologic and tectonic maps of Taiwan, the largest exposure of ultramafite (N-S trending, $30 \mathrm{~km}$ in length and $2 \mathrm{~km}$ wide) is located along the boundary between 
the basement complex and the slate belt (Ho 1982). Although magnetic susceptibility can have a wide range of values in rocks, the susceptibility of igneous rock is generally larger than that of metamorphic and sedimentary rocks (Langel and Hinze 1988). Considering the amplitude of the magnetic anomalies and their coverage, we propose a bold conjecture that a broad extrusive ultramafite body probably exists underneath the southern segment of the Central Range. Moreover, this new assertion could provide important information for meaningful planning of large-scale geophysical and geological surveys in inaccessible mountainous regions. It is possible that the previous concept of the orogeny of Taiwan, i.e., an alternating process between the Philippine Sea and Eurasia Plates, might be supplanted as a result of better and more comprehensive data.

\section{CONCLUSIONS}

The newly constructed magnetic anomaly map of Taiwan provides information concerning geological structures not previously available, especially in the mountain ranges. The map shows the range of magnetic anomalies mostly distributing between -400 to $400 \mathrm{nT}$ in Taiwan. The anomalies in the southern part of Taiwan are much higher than that of in the northern part whilst anomalies in the western plains area are higher than those of the mountainous ranges.

A high-frequency, positive magnetic anomaly trending NE-SW manifests as a prominent, continuous high from the Peikang basement high, extending as far as central Taiwan. Another high-frequency anomaly is found in southwestern Taiwan. Over a major part of the Backbone Range and the Hsuehshan Range shows smooth and gentle magnetic anomalies. Magnetic anomaly distributions of the mountain ranges reflect the metamorphic rocks of those regions, composed of low-susceptibility materials. Interestingly, the southern segment of the Central Range is in a conspicuous magnetic anomaly with about a 500-nT anomalous range, over an area of roughly $50 \times 50 \mathrm{~km}^{2}$. According to the amplitude of magnetic anomalies and their coverage, this finding implies that a broad extrusive ultramafite body probably exists underneath the southern segment of the Central Range. This result clearly requires further study, which we will undertake using seismic experiments to better understand the mechanisms and the nature of the magnetic anomaly.

Acknowledgements We are indebted to Ta-Liang Teng, Bor-Shouh Huang, Chau-Huei Chen, Chien-Hsin Chang, and many field-workers. The authors express their sincere appreciation to Chao-Hsing Lee, Lun-Tao Tong, and an anonymous reviewer for critical reviews and excellent suggestions on this manuscript. This study was sponsored by the Ministry of Education Grant under the iSTEP project at the National Central University. This research was partially supported by the Institute of Earth Sciences, Academia Sinica and the Taiwan Earthquake Research Center (TEC) funded through National Science Council. The TEC contribution number for this article is 00031 .

\section{REFERENCES}

Barton, C. E., 1997: International geomagnetic reference field: the seventh generation. J. Geomagn. Geoelectr., 49, 123148.

Chang, S. L. and C. C. Hu, 1981: Gravity and magnetic anomalies of Taiwan and their tectonic implication. Mem. Geol. Soc. China, 4, 121-142.

Chapman, S. and J. Bartels, 1940: Geomagnetism, Vol. I: Geomagnetic and Related Phenomena, Vol. II: Analysis of Data and Physical Theories, Oxford Univ. Press, Oxford, Landon.

Chen, C. H., 1975: Petrological and chemical study of volcanic rocks from Tatun Volcano group. Proc. Geol. Soc. China, 18, 59-72.

Chen, C. H., 2005: Study of total magnetic field in temporal and spatial variations in Taiwan (1989 2004). Ph.D. Thesis, National Central University of Taiwan. (in Chinese)

Chen, C. H., J. Y. Liu, H. Y. Yen, X. Zeng, and Y. H. Yeh, 2004: Changes of geomagnetic total field and occurrences of earthquakes in Taiwan. Terr. Atmos. Ocean. Sci., 15, 361370.

Chou, J. T., 1973: Sedimentology and paleogeography of the upper Cenozoic system of western Taiwan. Proc. Geol. Soc. China, 16, 111-144.

Gao, T. and H. Huang, 1994: Tectonic characteristics and evolution of the Taiwan Strait. Acta Geological Sinica, 68, 3, 197-207.

Ho, C. S., 1982: Tectonic evolution of Taiwan: Explanatory text of the tectonic map of Taiwan, The Ministry of Economic Affairs, Taipei, Taiwan, ROC, 126 pp.

Horng, C. S., C. Laj, T. Q. Lee, and J. C. Chen, 1992: Magnetic characteristics of sedimentary rocks from the Tsengwenchi and Erhjen-chi section in southwestern Taiwan. Terr. Atmos. Ocean. Sci., 3, 519-532.

Hsieh, S. H. and C. C. Hu, 1972: Gravity and magnetic studies of Taiwan. Petrol. Geol. Taiwan, 10, 283-321.

Hsu, S. K., C. S. Liu, C. T. Shyu, S. Y. Liu, J. C. Sibuet, S. Lallemand, C. Wang, and D. Reed, 1998: New gravity and magnetic anomaly maps in the Taiwan-Luzon region and their preliminary interpretation. Terr. Atmos. Ocean. Sci., 9, 509-532.

Huang, B. S., W. G. Huang, W. T. Liang, R. J. Rau, and N. Hirata, 2006: Anisotropy beneath an active collision orogen of Taiwan: Results from across islands array observations. Geophys. Res. Lett., 33, L24302, doi: 10.1029/2006 GL027844. [Link]

IAGA Division V-MOD, 2003: IGRF: International Geomagnetic Reference Field computing model, http://www.ngdc noaa.gov/IAGA/vmod/igrf.html. 
Langel, R. A. and R. A. Hinze, 1988: The magnetic field of the earth's lithosphere, Cambridge Univ. Press, America, doi: 10.2277/0521473330. [Link]

Lee, C. R. and W. T. Cheng, 1986: Preliminary heat flow measurements in Taiwan, The Fourth Circum-Pacific Energy and Mineral Resources Conference, Singapore.

Lee, T. Q., C. Kissel, E. Barrier, C. Laj, and W. R. Chi, 1991: Paleomagnetic evidence for a diachronic clockwise rotation of the Coastal Range, eastern Taiwan. Earth Planet. Sci. Lett., 104, 245-257, doi: 10.1016/0012-821X(91) 90207-X. [Link]

Lin, C. H., 2000: Thermal modeling of continental subduction and exhumation constrained by heat flow and seismicity in Taiwan. Tectonophysics, 324, 189-201, doi: 10.1016/ S0040-1951(00)00117-7. [Link]

Regan, R. D. and J. C. Cain, 1975: The use of geomagnetic field models in magnetic surveys. Geophysics, 40, 621-629, doi: 10.1190/1.1440553. [Link]

Sun, S. C. and Y. Y. Hsu, 1991: Overview of the Cenozoic geology and tectonic development of offshore and onshore Taiwan, Taicrust Workshop Proceedings, 35-47.

Tang, C. H., 1977: Late Miocene erosional unconformity on the subsurface Peikang High beneath the Chiayi-Yunlin coastal plain, Taiwan. Mem. Geol. Soc. China, 2, 155-168.

Torii, M., K. Fukuma, C. S. Horng, and T. Q. Lee, 1996: Magnetic discrimination of pyrrhotite- and greigite-bearing sediment samples. Geophys. Res. Lett., 23, 1813-1816, doi:
10.1029/96GL01626. [Link]

Tsai, Y. B., 1986: Seismotectonics of Taiwan. Tectonophysics, 125, 17-37, doi: 10.1016/0040-1951(86)90005-3. [Link]

Wang, C., C. P. Huang, L. Y. Ke, W. J. Chien, S. K. Hsu, C. T. Shyu, W. B. Cheng, C. S. Lee, and L. S. Teng, 2002: Formation of the Taiwan island as a solitary wave the Eurasian Continental Plate margin: Magnetic and seismological evidence. Terr. Atmos. Ocean. Sci., 13, 339-354.

Wu, F. T., 1978: Recent tectonics of Taiwan, in Geodynamics of the Western Pacific. In: Uyeda, S., R. W. Murphy, and K. Kobayashi (Eds.), J. Phys. Earth Suppl., 26, 265-299.

Wu, F., R. Rau, and D. Salzberg, 1997: Taiwan orogeny: thinskinned or lithospheric collision. Tectonophysics, 274, 191-220, doi: 10.1016/S0040-1951(96)00304-6. [Link]

Yeh, Y. H., Y. B. Tsai, and T. L. Teng, 1981: Investigations of geomagnetic total intensity in Taiwan from 1979 to 1981. Bull. Inst. Earth Sci. Academia Sinica, 1, 157-188.

Yen, H. Y., Y. H. Yeh, C. H. Lin, K. J. Chen, and Y. B. Tsai, 1995: Gravity survey of Taiwan. J. Phys. Earth, 43, 685696.

Yen, H. Y., Y. H. Yeh, and F. T. Wu, 1998: Two-dimensional crustal structures of Taiwan from gravity data. Tectonics, 17, 104-111, doi: 10.1029/97TC02697. [Link]

Yen, H. Y., C. H. Chen, Y. H. Yeh, J. Y. Liu, C. R. Lin, and Y. B. Tsai, 2004: Geomagnetic fluctuations during the 1999 Chi-Chi earthquake in Taiwan. Earth Planets Space, 56, 39-45. 